\title{
Studies in Vitamin A
}

\section{THE RELATIONSHIP BETWEEN BLOOD VITAMIN A LEVELS AND LIVER STORES IN RATS}

\author{
By J. GLOVER, T. W. GOODWIN AND R. A. MORTON \\ Department of Biochemistry, University of Liverpool
}

(Received 16 August 1946)

Variations in the vitamin A content of blood plasma have been the subject of much study. Neither in man nor in animals has any simple relationship been demonstrated between plasma levels and the amounts of vitamin stored in the liver. It is not necessary here to discuss all the data in which blood and liver determinations on individual animals were made, but brief reference to a few findings will suffice to put the problem in its setting.

Steigmann \& Popper (1944) claim that if the results for a large number of individuals are considered, a rough parallelism is observed between blood and liver levels. The data of Lewis, Bodansky, Falk \& McGuire (1942), however, carry the implication that plasma levels are controlled by a mechan. ism independent, to some extent at least, of the magnitude of the liver 'reserve'. In rats, the plasma levels remained between 37-53 i.u./100 ml. even when the animals received too little dietary vitamin A to allow accumulation in the liver. Ralli, Bauman \& Roberts (1941) and Josephs (1942) approached the problem from another direction and found that post-absorptive plasma levels in man and the rat were only slightly raised after large doses of vitamin A. The literature as a whole indicates the existence of a mechanism tending to resist change in plasma levels despite gross variations in vitamin $\mathbf{A}$ intake.

Gray, Hickman \& Brown (1940) and Gray \& Cawley (1942) fed vitamin A as free alcohol and as ester to rats. They concluded that both found their way to the liver to be stored as ester, but that analytical molecular distillation always revealed the presence in liver of very small amounts of vitamin as free alcohol. The vitamin A circulating in the blood is normally the alcohol (Clausen, Baum, McCoord, Rydeen \& Breese, 1942). It therefore seems possible that the liver level of unesterified vitamin is the variable controlling plasma levels. Since the determination of vitamin $\mathbf{A}$ in small amounts of plasma has been mastered and a chromatographic separation of free and esterified vitamin A worked out (Glover, Goodwin \& Morton, 1947), it became possible to test the above hypothesis.

\section{EXPERIMENTAL}

Estimation of vitamin $A$. Vitamin A was determined photoelectrically using the absorption maximum $(617 \mathrm{~m} \mu)$ in the antimony trichloride colour test. The instrument (Beckman spectrophotometer) gives readings of high accuracy at $E$ values from 0.2 to 1.2 , with 0.4 near the optimum as compared with 2.0 on a visual instrument. The amount of plasma needed is thus reduced to one-fifth and it was often possible to obtain enough plasma from a single rat for duplicate assays.

The rats used in most of the tests were males 6-9 months old reared on a balanced diet in the form of special rat cubes (Lever Brothers and Unilever Ltd.). This food contains a little vitamin A but not enough to give rise to significant pre-experimental variations in vitamin $A$ intake. The rats were divided into groups of three and were dosed orally by dropping $1 \mathrm{ml}$. of oil on to the back of the tongue from a small syringe. The oils were either tested fish liver oils or concentrates diluted to a definite potency with arachis oil.

In order to obtain rats with very low reserves of vitamin A, newly weaned animals were given the following vitamin A-free diet for 7-9 days: casein $20 \%$, rice starch $60 \%$, lard $10 \%$, salt mixture $5 \%$, marmite $5 \%$.

Collection and extraction of blood. At a stated time after dosing (3-14 days) and not less than $12 \mathrm{hr}$. after the last feeding, the rats are anaesthetized with chloroform and a small flap of skin reflected over the sternum. Blood is drawn after cardiac puncture into a syringe moistened inside with heparin solution. The sample is transferred to a centrifuge tube and the plasma separated by spinning. The plasma is poured into a measuring cylinder and then transferred to a small separating funnel. An equal vol. of ethanol is introduced into the same cylinder, and after stirring is added slowly and with constant shaking to the plasma (cf. Yudkin, 1941). Vitamin A is then extracted by shaking twice with an equal vol. of light petroleum (b.p. $40-60^{\circ}$ ). The combined extracts are freed from solvent on a warm water-bath and the residue made up to an appropriate vol. with ethanol-free chloroform.

Extraction of liver tissue. The freshly removed liver is freed from adhering tissue and weighed. It is then finely ground in a mortar with approx. 5 times its weight of anhydrous $\mathrm{Na}_{2} \mathrm{SO}_{4}$ and a little acid-washed silver sand. The homogenized mixture is transferred to a $250 \mathrm{ml}$. conical beaker and extracted once with $150 \mathrm{ml}$. and then twice with $75 \mathrm{ml}$. portions of ethyl ether freshly redistilled 
over reduced iron. Extraction is facilitated by rapid stirring of the contents of the beaker on a warm water-bath for 2 min. The beaker is allowed to stand for a few minutes when most of the ether may be decanted, and the remainder removed by filtration through a Buchner funnel. The three extracts are combined and the ether removed on a waterbath, the last traces in a stream of nitrogen. The residue is dissolved in light petroleum (b.p. 40-60 ) and examined for free and combined vitamin $\mathbf{A}$ as previously described.

\section{RESULTS}

The data sought for single animals, or sometimes groups of similarly dosed animals, were (a) plasma vitamin $A,(b)$ free vitamin $A$ in liver, and (c) esterified liver vitamin A. The liver storage for animals receiving very large doses fell below expectations but the effect has not yet been fully studied. The main findings are collected in Table 1. The highest dosage was in the form of an arachis oil tions during the most careful chromatography are relatively large (e.g. the loss of $2 \mathrm{i} . \mathrm{u} . / \mathrm{g}$. in a sample containing $15 \mathrm{i} . \mathrm{u} . / \mathrm{g}$. is much more serious than the same loss from a sample with a potency of 150 i.u./ g.). It seems justifiable to assume that an estimate of the content of vitamin $\mathbf{A}$ alcohol obtained indirectly by subtracting the potency of the ester fraction from the total is more accurate than the direct measurement when this is less than $100 \mathrm{i.u.} / \mathrm{g}$.

The relationship between plesa levels and the concentration of unesterified vitamin in the liver is linear. This is shown in Fig. $1(a)$ where plasma levels in i.u. $/ 100 \mathrm{ml}$. are plotted against liver alcohol in i.u./g. Fig. $1(b)$ illustrates the much greater deviation when the same blood values are plotted against total vitamin $A$ concentration in the livers. The points for these graphs were obtained by dividing the data into groups in which plasma values

Table 1. The relation between vitamin A plasma levels and free and total liver levels in rats

\begin{tabular}{|c|c|c|c|c|c|c|c|c|c|c|}
\hline \multirow{4}{*}{$\begin{array}{c}\text { Vitamin A } \\
\text { administered } \\
\text { (i.u.) }\end{array}$} & \multirow{4}{*}{$\begin{array}{l}\text { Time } \\
\text { after } \\
\text { dosing } \\
\text { (days) }\end{array}$} & & & \multirow{2}{*}{\multicolumn{2}{|c|}{$\begin{array}{l}\text { Vitamin A in plasma } \\
\text { (i.u. } / 100 \mathrm{ml} .)\end{array}$}} & \multicolumn{5}{|c|}{$\begin{array}{c}\text { Vitamin A in liver } \\
\text { (i.u./g.) }\end{array}$} \\
\hline & & \multirow{2}{*}{\multicolumn{2}{|c|}{ Weight of }} & & & \multicolumn{3}{|c|}{ Alcohol } & \multirow[b]{3}{*}{$\begin{array}{l}\text { Alcohol } \\
(\%)\end{array}$} & \multirow[b]{3}{*}{$\begin{array}{c}\text { Ester } \\
(\%)\end{array}$} \\
\hline & & & & & Mean & \multirow[b]{2}{*}{ Total } & \multirow{2}{*}{$\begin{array}{l}\text { Individual } \\
\text { value }\end{array}$} & \multirow{2}{*}{$\begin{array}{l}\text { Mean } \\
\text { value for } \\
\text { group }\end{array}$} & & \\
\hline & & $\begin{array}{l}\text { Rat } \\
\text { (g.) }\end{array}$ & $\begin{array}{l}\text { Liver } \\
\text { (g.) }\end{array}$ & $\begin{array}{l}\text { Individual } \\
\text { value }\end{array}$ & $\begin{array}{l}\text { value for } \\
\text { group }\end{array}$ & & & & & \\
\hline \multicolumn{11}{|l|}{ ddult male rats: } \\
\hline 0 & - & - & $7 \cdot 96$ & 38 & \multirow{3}{*}{35} & 71 & 13 & \multirow{3}{*}{25} & \multirow{3}{*}{11} & \multirow{3}{*}{89} \\
\hline 10,000 & 5 & 241 & $9 \cdot 03$ & 36 . & & 307 & 22 & & & \\
\hline 10,000 & 5 & 183 & $6 \cdot 88$ & $31)$ & & 285 & 40 & & & \\
\hline 0 & - & - & $8 \cdot 42$ & $46\}$ & \multirow{3}{*}{45} & 278 & 52 & \multirow{3}{*}{58} & \multirow{3}{*}{18} & \multirow{3}{*}{82} \\
\hline 10,000 & 4 & 224 & $9 \cdot 00$ & $44\}$ & & 372 & 64 & & & \\
\hline 50,000 & $\overline{3}$ & 219 & $7 \cdot 56$ & 57 ) & & 636 & 61 & & & \\
\hline 50,000 & 4 & 215 & $7 \cdot 36$ & 55 & \multirow[t]{2}{*}{56} & 3,605 & 135 & \multirow[t]{2}{*}{125} & \multirow[t]{2}{*}{6} & \multirow[t]{2}{*}{94} \\
\hline 50,000 & 7 & 206 & $8 \cdot 48$ & 57) & & 2,020 & 180 & & & \\
\hline 150,000 & $\mathbf{5}$ & 206 & $6 \cdot 19$ & 67 & 67 & 4,030 & 145 & 145 & \multirow{3}{*}{3} & 96 \\
\hline 500,000 & 10 & 210 & $6 \cdot 30$ & 75 & \multirow{2}{*}{75} & 8,190 & 175 & \multirow{2}{*}{228} & & \multirow{2}{*}{97} \\
\hline 150,000 & 6 & 202 & $7 \cdot 55$ & $75\}$ & & $\mathbf{5 , 3 6 0}$ & 280 & & & \\
\hline $1,000,000$ & 7 & 145 & $6 \cdot 67$ & $86)$ & \multirow{2}{*}{88} & 16,580 & 271 & \multirow{2}{*}{257} & 3 & \\
\hline $100,000 *$ & 4 & 553 & $19 \cdot 85$ & $90\}$ & & $\mathbf{3 , 2 7 0}$ & 243 & & 3 & 97 \\
\hline $1,000,000$ & 6 & 150 & $5 \cdot 85$ & 112 & 112 & 10,510 & 360 & 360 & 3 & 97 \\
\hline 150,000 & 7 & 170 & $5 \cdot 67$ & 125 & 125 & 6,130 & 500 & 525 & 8 & 92. \\
\hline $500,000 \dagger$ & 6 & - & $44 \cdot 62$ & $124\}$ & 125 & 7,400 & 549 & $52 b$ & 8 & 92. \\
\hline $500,000^{*}$ & 14 & 553 & 20.95 & 147 & 147 & 13,500 & 618 & 618 & 5 & 95 \\
\hline 500,000 & 6 & 170 & $5 \cdot 59$ & 183 & 183 & 11,040 & 820 & 820 & 7 & 93 \\
\hline young rats: & & & & & & & & & & \\
\hline 0 & - & 348 & $17 \cdot 62$ & 50 & 50 & $15^{\circ}$ & - & $\ll 15$ & - & - \\
\hline young rats: & & & & & & & & & & \\
\hline $\begin{array}{l}\text { Depleted of } \\
\text { vitamin for }\end{array}$ & 一 & - & $18 \cdot 04$ & 47 & 47 & 4 & $2 \cdot 6$ & $2 \cdot 6$ & 65 & 35 \\
\hline 7 days & & & Group & 3 rats. & $+c$ & ps of 6 & & & & \\
\hline
\end{tabular}

solution of a rich (30\%) vitamin alcohol concentrate (British Drug Houses Ltd., molecular distillate), but apart from this ester preparations were used. The figures confirm the observation of Gray et al. (1940) that vitamin A, whether fed as free alcohol or ester, is stored in the liver overwhelmingly as ester.

Livers of rats with small vitamin A stores contain only minute amounts of the alcohol. In such cases the slight losses which occur in the alcohol frac- were within a limit of $10 \mathrm{i.u.} / 100 \mathrm{ml}$. (e.g. between 30 and 40, 40 and 50 i.u./100 ml.). The mean plasma levels in each of these groups were plotted against the corresponding mean values for the total or alcohol concentration in the livers (see Table 1).

In Fig. 1 the curve does not pass through the origin but cuts the ordinate at a point representing a plasma level of 35-40 i.u./100 ml. Thus at zero liver storage the plasma level is still 35-40 i.u./100 ml. indicating that physiological needs must be satisfied 
by maintenance at this level before liver storage occurs. This confirms the findings of Lewis et al. (1942). Even more direct evidence was supplied by two experiments carried out on almost depleted young rats ( $\mathrm{B}$ in Table 2 ) in which it was found that the blood values were maintained at 47 and 50 i.u./ $100 \mathrm{ml}$. respectively, even when liver stores were almost nil. In these cases, accurate estimations of vitamin A ester could not be demonstrated. It seems that absorption is complete within 4 days and all subsequent tests except one were carried out on rats kept for at least 4 days after dosing. The exception, in which a rat kept only 3 days was used, appears in retrospect entirely normal.

Although rats were killed not less than $12 \mathrm{hr}$. after feeding, there was also a possibility that

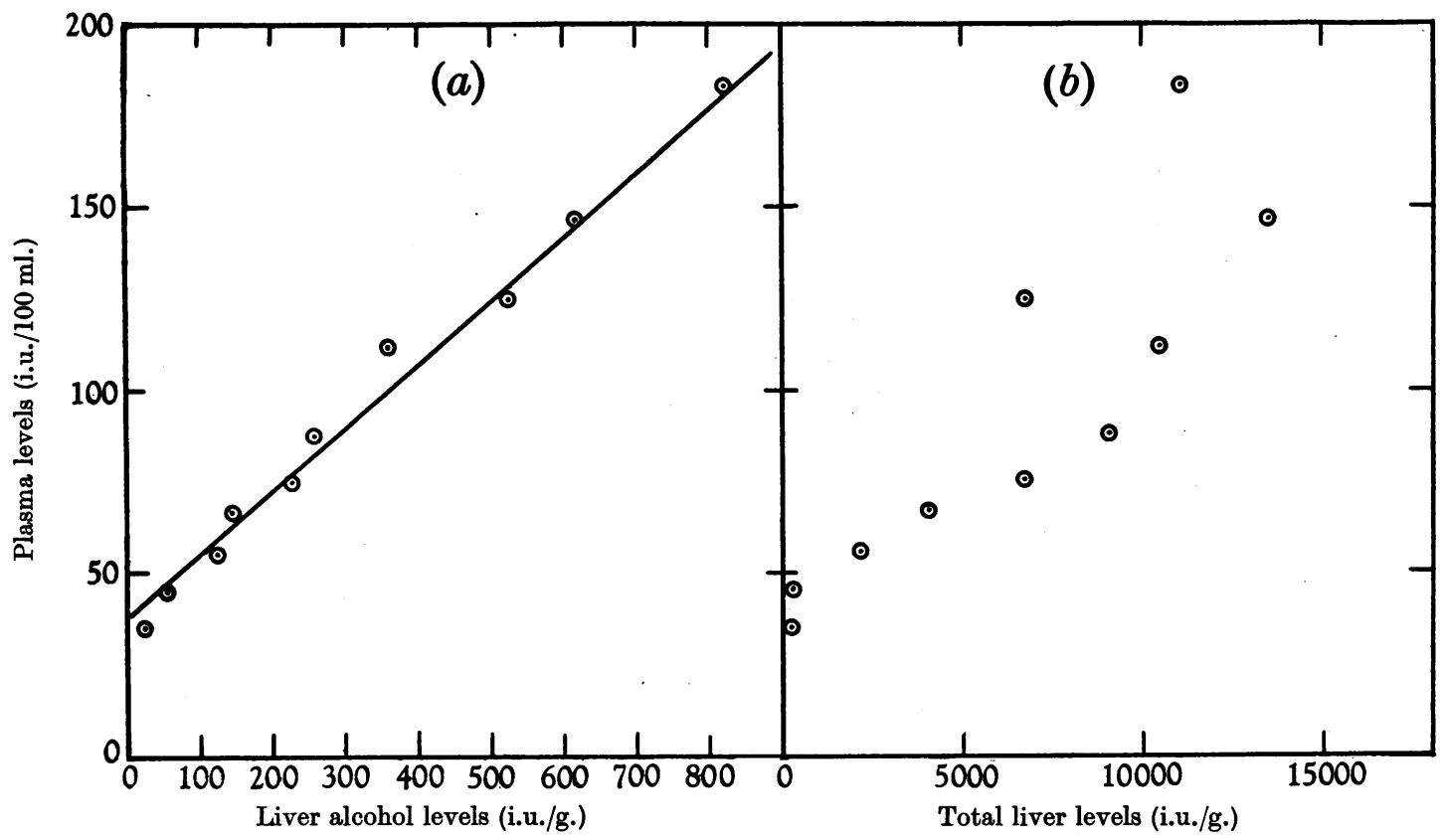

Fig. 1. (a), relation between vitamin A plasma levels and liver alcohol levels. (b), relation between vitämin A plasma levels and total liver levels.

free vitamin A were difficult for livers of such low potency, but it was proved that a considerable proportion of the vitamin $A$ in the livers of the rats existed in the free form.

\section{Rate of absorption of large doses of vitamin $A$}

In this part of the work it was essential that the plasma samples examined should be free from vitamin A ester in transit. Ester is present during active absorption, for the free vitamin $A$ liberated in the alimentary tract by intestinal enzymes is resynthesized to ester during passage through the gut wall (Gray \& Cawley, 1942) and it is this esterified vitamin A in transport to the liver which, superimposed on the normal vitamin A alcohol content of the plasma, gives rise to the typical tolerance curve.

The time required therefore to complete the absorption of vitamin $A$ supplements had to be determined. A pooled sample of plasma from rats killed 4 days after dosing each with 100,000 i.u. was examined chromatographically and the presence of

absorption of small amounts of vitamin $\mathbf{A}$ from the stock diet might still be taking place. No vitamin A ester could be demonstrated in the plasma of normal animals killed $12 \mathrm{hr}$. after feeding.

Table 2. Effect of autolysis on vitamin $A$ content of liver tissue

Conditions of storage
A. Fresh
$24 \mathrm{hr}$. at room temp.
B. Fresh
$72 \mathrm{hr}$. in ice-chest
C. Fresh
$24 \mathrm{hr}$. at room temp.
D. Fresh $48 \mathrm{hr}$. at room temp.
E. Fresh
$24 \mathrm{hr}$. at room temp.

Autolytic processes which set in immediately after removal of the liver could conceivably cause

$\begin{array}{cc}\text { Vitamin A (i.u./g. liver) } \\ \text { Total } & \text { Freo } \\ 181 & 35 \\ 173 & 46 \\ 71 & 14 \\ 70 & 10 \\ 372 & 66 \\ 348 & 57 \\ 307 & 21 \\ 291 & 14 \\ 631 & 58 \\ 578 & 74\end{array}$


hydrolysis of the esterified vitamin A. If this occurred to any appreciable extent, delay in examining the livers could lead to very misleading results. A number of experiments were carried out to determine the extent of hydrolysis of esterified vitamin $\mathbf{A}$ under varying conditions and times of storage. The results obtained (Table 2) prove that rat livers may be kept at room temperature for some hours before examination, and even $48 \mathrm{hr}$. standing caused losses no greater than $5 \%$ and did not alter appreciably the ester/alcohol ratio.

\section{DISCUSSION}

Our results make it probable that the plasma vitamin A level of rats is maintained by, and is proportional to, the free vitamin A concentration in the liver. The - underlying mechanism remains obscure but it obviously tends to maintain the vitamin A status quo of the blood. Normal plasma values for rats vary between 35 and 50 i.u. $/ 100 \mathrm{ml}$. and in order to maintain such levels after large doses of vitamin A the equilibrium,

$$
\text { vitamin A ester } \rightleftharpoons \text { vitamin A alcohol + fatty acid, }
$$

moves far to the left. Under reversed conditions, when liver stores are almost exhausted, the equilibrium is displaced to the right so as to maintain the normal concentration of functional vitamin $\mathbf{A}$ (alcohol) in the plasma, e.g. total liver store 13,500 i.u./g., \% free vitamin A $5 \%$; total liver store 4 i.u./g., \% free vitamin A $65 \%$.

The recent work of Sobotka, Kann \& Winternitz (1944) on the differences in fluorescence exhibited by vitamin A esters and the free alcohol provides an explanation of the results obtained by Popper \& Brenner (1942) on the fluorescence of vitamin $A$ in the liver cells. The cytoplasmic fluorescence typical of vitamin A alcohol fades quickly, whereas the fluorescence of lipid droplets rises to a peak after a few seconds and then gradually fades; this behaviour is characteristic of esterified vitamin A. The implications of the above interpretation are that the vitamin A alcohol is dispersed in an aqueous medium (probably as a protein complex) whilst the ester occurs in the fat droplets; furthermore, an esterase converting the ester to alcohol might be expected to function only at an oil-water interface. The amount of ester brought into contact with the enzyme would then be directly proportional to the area of this interface; the vitamin $A$ concentration in the droplets would be less important. The amount of interaction is thus probably determined by the surface area of the droplets since by alteration of size or number of droplets present, the amount of vitamin A ester exposed to the enzyme could be raised considerably without alteration in the concentration of vitamin $A$ in the droplets themselves. The further observation of Popper \& Brenner (1942), that as rats are depleted of vitamin $A$ the droplets in the liver which fluoresce become smaller and more numerous, fits well. To convert more ester into alcohol, more ester is exposed to the enzyme by an increase in interfacial area (more droplets). Recent reports suggest that, although normal therapeutic doses of vitamin $\mathbf{A}$ are ineffective in improving the health of patients with no history of vitamin A deprivation, massive doses can confer considerable clinical benefits (e.g. Dunlap \& Loken, 1942; Straumfjord, 1942). Our observations offer a possible explanation. An increase in the supply of vitamin A to the various organs of the body requires a considerable rise in functional vitamin $\mathbf{A}$ in the plasma. This can only be achieved by quite massive dosing.

\section{SUMMARY}

1. The plasma vitamin A levels of rats are proportional to the concentrations of vitamin $A$ alcohol in the livers, but are not proportional to the total liver stores of vitamin A which consist mainly of esters.

2. Plasma vitamin A levels are maintained near normal (35-40 i.u./100 ml.) even when liver stores approach exhaustion.

3. Autolysis of intact liver at room temperature for $48 \mathrm{hr}$. does not result in hydrolysis of esterified vitamin $\mathbf{A}$ or in destruction of vitamin $\mathbf{A}$ to any appreciable extent.

4. The implications of the results are discussed in relation to vitamin $A$ therapy in man.

We are indebted to the Medical Research Council for a grant and one of us (J. G.) holds a Musgrave Studentship of Queen's University, Belfast.

\section{REFERENCES}

Clausen, S. W., Baum, W. S., McCoord, A. B., Rydeen, J. O. \& Breese, B. C. (1942). J. Nutrit. 24, 1.

Dunlap, K. \& Loken, R. D. (1942). Science, 95, 554.

Glover, J., Goodwin, T. W. \& Morton, R. A. (1947). Biochem. J. 41, 94.

Gray, E. Le B. \& Cawley, J. D. (1942). J. Nutrit. 23, 301.

Gray, E. Le B., Hickman, K. C. D. \& Brown, E. F. (1940). J. Nutrit. 19, 39.

Josephs, H. W. (1942). Johns Hopk. Hosp. Bull. 71, 253.
Lewis, J. M., Bodansky, O., Falk, K. G. \& McGuire, G. (1942). J. Nutrit. 23, 431.

Popper, H. \& Brenner, S. (1942). J. Nutrit. 23, 431.

Ralli, E. P., Bauman, E. \& Roberts, L. (1941). J. clin. Invest. 20, 709.

Sobotka, H., Kann, S. \& Winternitz, W. (1944). J. biol. Chem. 152, 635.

Steigman, F.\& Popper, H. (1944). Amer.J.med.Sci.207,468. Straumfjord, J. W. (1942). N.W. Med. 41, 229, quoted in Ann. Rev. Biochem. (1943), 12, 370.

Yudkin, S. (1941). Biochem. J. 35, 551. 